\title{
Etanercept biosimilar associated with Guillain-Barré syndrome: insights from a case
}

\author{
V. Shobha ${ }^{1}$, A.M. Desai ${ }^{1}$, T. Matthew ${ }^{2}$ \\ 'Department of Clinical Immunology and Rheumatology, St. John's National Academy of Health Sciences, \\ Bengaluru, India; 'Department of Neurology, St. John's National Academy of Health Sciences, Bengaluru, India
}

\section{SUMMARY}

Anti-tumor necrosis factor drugs are used routinely according to treatment guidelines for several chronic rheumatologic problems. However, a rare and usually unpredictable adverse drug reaction namely peripheral nervous system demyelination is being increasingly recognized. Biosimilars are gaining momentum especially in countries like India. Hence, we report a case of Guillain-Barré syndrome secondary to an etanercept biosimilar, probably the first case reported so far.

Key words: Ankylosing spondylitis; Guillain-Barré syndrome; anti TNF therapy; etanercept biosimilar.

Reumatismo, 2019; 71 (2): 99-102

\section{INTRODUCTION}

A nti TNF drugs are used routinely according to treatment guidelines for several chronic rheumatologic problems including spondyloarthropathy (1). Biosimilars are gaining momentum especially in countries like India and the United Kingdom. We report a case of Guillain-Barré syndrome secondary to an etanercept biosimilar, probably the first case reported so far.

\section{CASE REPORT}

A 24-year-old male with no other known co-morbidities was diagnosed as having ankylosing spondylitis (AS). The symptoms at initial presentation include inflammatory back pain with oligoarthritis involving $\mathrm{B} / \mathrm{L}$ knees, ankles. Magnetic resonance imaging (MRI) SI joint showed B/L sacroiliitis and HLA B27 was positive.

His BASDAI score was 23.6. He had responded poorly to NSAIDs and was bedridden due to $\mathrm{B} / \mathrm{L}$ knee arthritis and back pain. He underwent a screening check for biologics which included chest radiography, which was normal; Mantoux, IGRA,
$\mathrm{HIV}, \mathrm{HbsAg}$, and $\mathrm{HCV}$ were negative. There was no past or family history of any demyelinating disorder or any other connective tissue disorder.

He was initiated with intacept (etanercept biosimilar) dose $50 \mathrm{mg}$ per week subcutaneously. Three weeks later he reported dramatic improvement in symptoms and was able to walk with minimal discomfort. His BASDAI score reduced to 2.6.

Three weeks after assessment, the patient reported weakness in both lower limbs with buckling in the last four 4 days. On examination, power was $3 / 5$ in both lower limbs and reflexes were sluggish. There were no other complaints such as fever, malaise to suggest any preceding infection. A viral screen which included HIV, hepatitis $\mathrm{B}$, hepatitis $\mathrm{C}$ and Cytomegalovirus was done; all tests were negative. There was no family or previous history of a demyelinating syndrome. He was referred to the Neurology Department immediately and the diagnosis of Guillain-Barré syndrome (GBS) was confirmed as the nerve conduction study showed an acquired segmental demyelinating polyneuropathy. MRI spine study was within normal limits and CSF
Corresponding author: Anu Mohan Desai

Department of Clinical Immunology and Rheumatology

St. John's National Academy

of Health Sciences, Bengaluru, India

E-mail: dranumohan@gmail.com 
showed a raised protein level and a normal cellular count.

The patient was initiated on high dose dexamethasone. As the lower limb weakness progressed, he received 5 days of intravenous immunoglobulin (IvIg), adjusted as per patient body weight (1080 mg). Post IvIg, he showed improvement as he was able to stand by himself and walk with support. The patient recovered fully from GBS after 2 months and is doing well on follow up.

\section{DISCUSSION}

According to the NHS, a biosimilar is defined as a biological medicine which is highly similar to another biological medicine already licensed for use. It is shown to not have any clinically meaningful differences from the originator biological medicine in terms of quality, safety and efficacy. However, biosimilars are not considered generic equivalents to their originator biologic because the two products are not completely identical. A biosimilar must also satisfy rigorous regulatory requirements in terms of comparative quality, safety and efficacy.

GBS is defined as an acute demyelinating peripheral neuropathy causing limb weakness that can progress over days or weeks. The annual incidence is 1.5 cases per 100,000 and has a mortality rate of $5 \%$. It is estimated that approximately $10 \%$ of patients will be disabled by one year (2).

It is postulated that TNF $\alpha$ antagonist therapy could promote the development of GBS by boosting the number of activated peripheral $\mathrm{T}$ cells or by disturbing the intrinsic balance of TNF $\alpha$ and its receptors in the peripheral nervous system compartment (3).

It is also equally important to consider the temporal association of the demyelinating event following exposure to anti-TNFa treatment and the resolution or relapse of signs and symptoms after cessation of therapy.

A recently conducted French national survey (4) reviewed 33 patients who developed demyelination secondary to vari- ous anti TNF agents: 22 had CNS and 11 peripheral nervous system (PNS) involvement. Only 2 patients were found to have acute inflammatory demyelinating polyneuropathy ( $\mathrm{n}=2$ confirmed by CSF analysis and nerve conduction studies. Overall, a causal relationship between anti-TNF- $\alpha$ was established as probable in 31 patients and definite in 2 who had positive rechallenge. A case control study in an administrative database cohort of more than 10,000 patients with rheumatoid arthritis has suggested that anti-TNF $\alpha$ agents are associated with an approximately $30 \%$ increase in the risk of a demyelinating event (5). Psarelis et al. (6) presented a very similar case of a 50-year-old male AS patient who developed GBS post etanercept injections. The article has also suggested the use of IL-17 blockers as a safer alternative to TNF inhibitors.

TNF $\alpha$ is secreted by microglia and macrophages in the CNS and is believed to have a direct role in the etiopathogenesis of demyelination $(7,8)$. TNF $\alpha$ exists in two forms: a transmembrane protein (tmTNF) and a soluble form (sTNF) which interact with two distinct receptors, TNFR1 and TNFR2. sTNF shows greater affinity with TNFR1, which contains a death domain that signals cell apoptosis. The TNFR2 has a complex function that does not involve a death domain, instead signals proliferation of the cells based on poorly understood pathways. TNF $\alpha$ has been found to play a key role in myelin and oligodendrocyte damage $(7,8)$. In the initial stages of the disease, it is believed to cause demyelination; however in later stages, it is essential for remyelination (9). High levels of markers of T cell activation such as TNF $\alpha$ and other cytokines have been demonstrated in the serum of patients with GBS (10). Elevated levels of TNF $\alpha$ have been detected in the serum of affected patients, which strongly correlate with disease severity, and normalize in parallel with the clinical recovery of patients (11). However, TNF $\alpha$ also has several immunoregulatory functions such as suppression of $\mathrm{T}$ cell reactivity to autoantigens in animal models of autoimmunity (12). TNF $\alpha$ deficiency also re- 
sults in failed regression of myelin-specific $\mathrm{T}$ cell reactivity and prolonged survival of activated $\mathrm{T}$ cells (13).

Repeated injections of a TNF $\alpha$ antagonist cause blockage of endogenous TNF, resulting in enhancement of $\mathrm{T}$ cell proliferative responses and cytokine production (12). Hence, it is believed that the prolonged administration of TNF $\alpha$ antagonists can enhance autoimmune responses by augmenting $\mathrm{T}$ cell receptor signaling and decreasing apoptosis of autoreactive $\mathrm{T}$ cells (14). TNF $\alpha$ antagonists are parentally administered and can gain access to the peripheral nervous system at the roots and motor nerve terminals in areas where the blood-nerve barrier is absent or relatively deficient. This will result in a deficiency of $\mathrm{TNF} \alpha$ within the peripheral nervous system compartment which will in turn prolong the myelin specific $\mathrm{T}$ cell response and increase the risk of developing or prolonging an immune-mediated neuropathy (15).

In summary, it is postulated that TNF $\alpha$ antagonist therapy could promote the development of GBS by boosting the number of activated peripheral $\mathrm{T}$ cells or by disturbing the intrinsic balance of TNF $\alpha$ and its receptors in the peripheral nervous system compartment (16).

\section{CONCLUSIONS}

In conclusion we have presented a case of etanercept biosimilar induced GBS which responded to standard therapy of IvIg. Such adverse reactions are rare but can result in high morbidity and are difficult to predict.

We reiterate that systematic and long-term monitoring while receiving biologics and biosimilars is the need of the millennium.

\section{Key message}

Biosimilars and biologics share similar adverse event risks and mandate vigilant monitoring.

Ethical statement: the study has received approval of the institutional ethics committee.
Conflict of interest: the authors declare no conflicts of interest.

\section{REFERENCES}

1. Keat A, Barkham N, Bhalla A, et al. BSR guidelines for prescribing TNF- $\alpha$ blockers in adults with ankylosing spondylitis. Report of a working party of the British Society for Rheumatology. Rheumatology 2005; 44: 939-47.

2. Silburn S, McIvor E, McEntegart A, Wilson H. Guillain-Barré syndrome in a patient receiving anti-tumour necrosis factor [alpha] for rheumatoid arthritis: a case report and discussion of literature. Ann Rheum Dis. 2008; 67: 575.

3. Shin IS, Baer AN, Kwon HJ, et al. GuillainBarré and Miller Fisher syndromes occurring with tumor necrosis factor $\alpha$ antagonist therapy. Arthrit Rheumatol. 2006; 54: 1429-34.

4. Seror R, Richez C, Sordet C, et al. Pattern of demyelination occurring during anti-TNF- $\alpha$ therapy: a French national survey. Rheumatology 2013; 52: 868-74.

5. Bernatsky S, Renoux C, Suissa S. Demyelinating events in rheumatoid arthritis after drug exposures. Ann Rheum Dis. 2010; 69: 1691-3.

6. Psarelis S, Hajineocli AP, Hadjicosta E, et al. Is secukinumab a safe alternative treatment for ankylosing spondylitis with Guillain Barré syndrome after anti-TNF- $\alpha$ treatment? Case report and literature review. Clin Rheumatol. 2017; 36: 1197-9.

7. Kassiotis G, Kollias G. Uncoupling the proinflammatory from the immunosuppressive properties of tumor necrosis factor (TNF) at the p55 TNF receptor level: implications for pathogenesis and therapy of autoimmune demyelination. J Exper Med. 2001; 193: 427-34.

8. Selmaj KW, Raine CS. Tumor necrosis factor mediates myelin and oligodendrocyte damage in vitro. Ann Neurol. 1988; 23: 339-46.

9. Andreadou E, Kemanetzoglou E, Brokalaki C, et al. Demyelinating disease following antiTNFa treatment: a causal or coincidental association? Report of four cases and review of the literature. Case Rep Neurol Med. 2013; 2013.

10. Hartung HP, Hughes RA, Taylor WA, et al. T cell activation in Guillain-Barre syndrome and in MS: elevated serum levels of soluble IL-2 receptors. Neurology 1990; 40: 215-8.

11. Sharief MK, McLean B, Thompson EJ. Elevated serum levels of tumor necrosis factor- in Guillain-Barre syndrome. Ann Neurol. 1993; 33: 591-6.

12. Cope A, Ettinger R, McDevitt H. The role of TNF and related cytokines in the development and function of the autoreactive T-cell repertoire. Res Immunol. 1997; 148: 307-12.

13. Kassiotis G, Kollias G. Uncoupling the proinflammatory from the immunosuppressive 
properties of tumor necrosis factor (TNF) at the p55 TNF receptor level: implications for pathogenesis and therapy of autoimmune demyelination. J Exp Med. 2001; 193: 427-34.

14. Cope AP, Liblau RS, Yang XD, et al. Chronic tumor necrosis factor alters $\mathrm{T}$ cell responses by attenuating $\mathrm{T}$ cell receptor signaling. $\mathrm{J}$ Exp Med. 1997; 185: 1573-84.
15. Tsang RS, Valdivieso-Garcia A. Pathogenesis of Guillain-Barre syndrome. Exp Rev Anti Infect Ther. 2003; 1: 597-608.

16. Shin IS, Baer AN, Kwon HJ, Papadopoulos EJ, Siegel JN. Guillain-Barré and Miller Fisher syndromes occurring with tumor necrosis factor $\alpha$ antagonist therapy. Arthrit Rheumatol. 2006; 54: 1429-34. 